\title{
Revisando as anisometropias
}

\author{
Reviewing anisometropias
}

Sidney Júlio de Faria e Sousa ${ }^{1}$

\begin{tabular}{|l|}
\hline \multicolumn{1}{|c|}{ RESUMO } \\
\hline O trabalho apresenta uma revisão crítica das anisometropias. Discute a \\
definição, classificação e os prováveis mecanismos ópticos e fisiológicos \\
da sintomatologia. Não existem regras rígidas de tratamento do problema, \\
cabendo ao médico a tomada de decisões individualizadas para cada \\
paciente.
\end{tabular}

Descritores: Anisometropia; Ametropias; Erros de refração

As anisometropias constituem um dos campos mais polêmicos da prática refratométrica. Anisometropia é o nome que se dá à condição em que o erro refrativo é diferente entre os olhos. Seria interessante se houvesse, na definição, um valor limítrofe que identificasse os casos clinicamente significantes. Infelizmente isso não acontece uma vez que as diferenças refrativas sozinhas não são as únicas determinantes da tolerância à condição. Outros fatores, como o tipo de anisometropia, idade do paciente, capacidade fusional, uso prévio de óculos e perfil psicológico, também contam.

O objetivo deste trabalho é apresentar uma revisão crítica das informações que possam auxiliar no raciocínio com as anisometropias. Como veremos, não existem regras gerais de conduta, cabendo ao médico a tomada de decisões individualizadas para cada paciente. $\mathrm{O}$ assunto é antigo, mas tem readquirido interesse com os avanços das cirurgias refrativas.

\section{CLASSIFICAÇ̃̃̃O}

As anisometropias são ditas miópicas quando os dois olhos são míopes e hipermetrópicas, quando ambos são hipermétropes. Dá-se o nome de antimetropia quando um olho é míope e o outro hipermétrope. Outra classificação divide-as em axiais e refrativas. A Figura 1 ajuda a entender essa classificação. Nela, o olho "a" é emétrope, porque seu sistema óptico, constituído pela córnea e cristalino desacomodado, foca a imagem na retina. Os olhos "b" e "c" são hipermétropes, porque formam imagens além da retina.

Se alguém possui um olho do tipo "a" e outro do tipo "b", por definição, terá uma anisometropia. Uma vez que ambos os olhos têm o mesmo poder (+60 D), o fato que caracteriza a anisometropia é a diferença dos seus comprimentos axiais. Por isso, ela é classificada como axial.

Se um olho é do tipo "a" e outro do tipo "c", estaremos ainda diante de uma anisometropia. Agora, a diferença não é mais no comprimento, mas no poder. O primeiro olho tem $+60 \mathrm{D}$ e o segundo, $+43 \mathrm{D}$. Esse tipo de anisometropia é conhecido como anisometropia refrativa.

${ }^{1}$ Professor Associado - Faculdade de Medicina de Ribeirão Preto-USP

Endereço para correspondência: Rua Hortêncio Mendonça Ribeiro 845 - Ribeirão Preto (SP) CEP 14025-590. E-mail: sidneyjfs@uol.com.br

\section{IMAGENS FORMADAS PELO OLHO}

Tanto as anisometropias axiais quantos as refrativas geram diferenças 


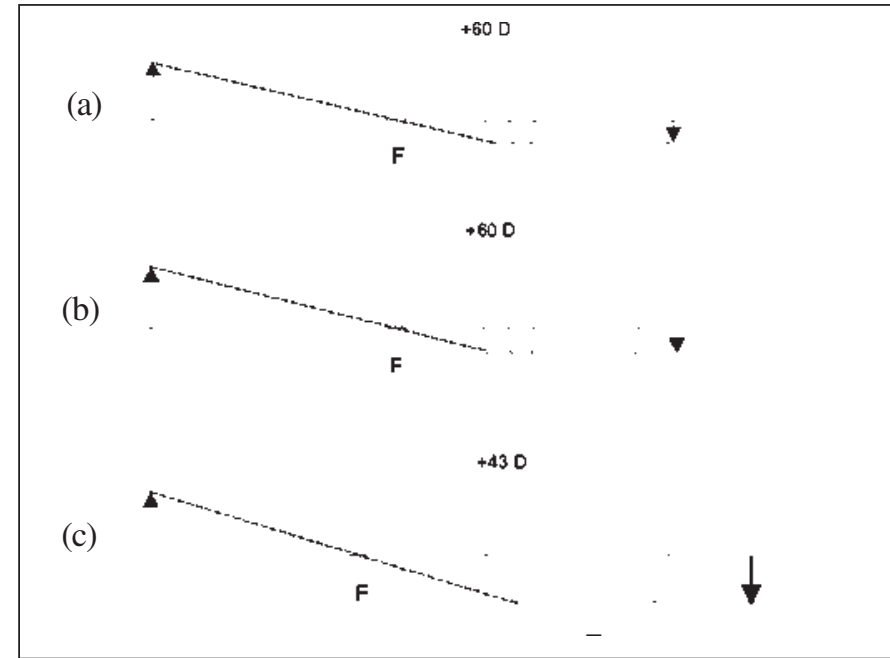

Figura 1 - Anisometropia axial e refrativa. F: foco anterior do olho

nos tamanhos das imagens retinianas. Isto porque os tamanhos das mesmas dependem das distâncias entre as retinas e os pontos nodais; quanto maiores as distâncias, maiores as imagens (Figura 2). Nas anisometropias axiais, os pontos nodais de ambos os olhos se superpõem, mas as retinas não; nas refrativas, as retinas se superpõem, mas, os pontos nodais não. Em ambos os casos, as distâncias retina - ponto nodal diferem entre os olhos, gerando o fenômeno.

Nas anisometropias, não corrigidas, além das diferenças de tamanho também ocorrem diferenças de nitidez entre os olhos. Porém, quando as imagens dos mesmos são focadas na retina, com óculos ou lentes de contato, a diferença de nitidez desaparece, deixando apenas a disparidade de tamanho. Essa disparidade de tamanho, entre imagens retinianas nítidas, recebe o nome de aniseiconia.

Como é difícil, para o cérebro, fundir imagens de tamanhos distintos, a aniseiconia tende a sobrecarregar o esforço fusional, gerando sintomas de cefaléia, desconforto, queimação, repuxão, prurido, fotofobia enfim, um conjunto de sensações que, neste trabalho, chamaremos de astenopia ${ }^{(1)}$.

\section{SINTOMATOLOGIA}

Já vimos que nas anisometropias, não corrigidas, existe uma diferença no tamanho e na nitidez das imagens retinianas. Na prática, a diferença de visão acaba dominando o quadro das queixas. É muito mais provável que um anisométrope

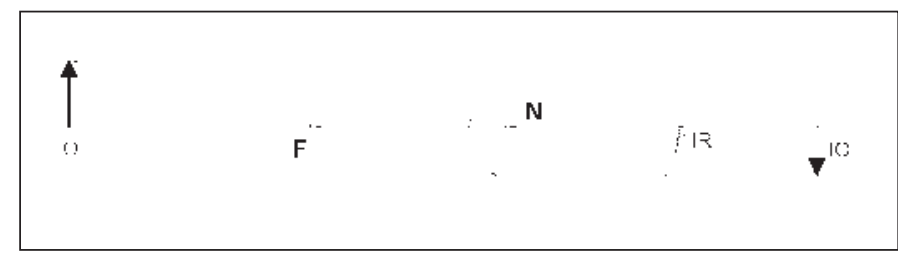

Figura 2 - Imagens do sistema óptico ocular. O: objeto; F: foco anterior; $\mathrm{N}$ : ponto nodal; IR: imagem retiniana; IO: imagem óptica queixe-se de turvação visual unilateral, dificuldade de percepção de profundidade ou que um olho atrapalha o outro, do que realmente de astenopia. A própria diferença de acuidade acaba desencorajando a fusão e, com isso, os sintomas associados a ela. O curso insidioso das anisometropias naturais, também dá tempo a que as pessoas se adaptem a elas. Não parece, pois, haver substrato fisiológico sólido para considerar as anisometropias, não corrigidas, como fontes importantes de astenopia.

Então, quando é que se esperam sintomas? A resposta é: quando se corrigem as anisometropias. Isto porque, a diminuição da turvação visual entre olhos, promovida pela correção, favorece o exercício da visão bifoveal. Com isso, imagens de diferentes tamanhos, que antes não podiam ser juntadas, devido à diferença de nitidez, passam a ser fundidas às custas de grandes esforços e sintomas variados.

Portanto, quando se depara com casos de anisometropias no adulto, faz-se necessário pesar as vantagens e desvantagens da sua correção. Existe sempre o risco das lentes gerarem sintomas até então inexistentes. As crianças são bem mais tolerantes. Nelas, não se deve hesitar prescrever o total da diferença refrativa entre os olhos, diante da mais tênue ameaça de ambliopia.

\section{PRINCÍPIOS DA CORREČ̃̃ DAS ANISOMETROPIAS}

Com a introdução da lente corretora no olho anisométrope, há uma modificação do poder do sistema que refrata a luz. Antes, ele era constituído apenas pelos meios refrativos do olho. Agora, passa a ser representado pela combinação lentear-olho. Vejamos como essa combinação afeta a anisometropia axial e refrativa.

A figura 3 mostra que a correção da anisometropia axial, apresentada em "b", cria um sistema óptico de poder diferente de "a", desfazendo o equilíbrio original de poder entre ambos $(+10,50 \mathrm{D}+60 \mathrm{D}$ vs. $+60 \mathrm{D})$. Como regra geral, quando se corrige uma anisometropia axial troca-se disparidade de refração por disparidade de poder, gerando aniseiconia. Portanto, o segredo do tratamento dessas anisometropias está na escolha da correção que interfira, o mínimo possível, com a igualdade de poder entre os olhos, minimizando a aniseiconia induzida.

Por outro lado, a correção da anisometropia refrativa, apresentada na Figura 3(c), resulta em benefício tanto na nitidez quanto no tamanho das imagens, uma vez que tende a diminuir simultaneamente as desigualdades dos vícios de refração e dos poderes (+12 D + 43 D vs. +60 D) de "a" e "c". Conclui-se que, o segredo do tratamento dessas anisometropias é escolha da correção que introduza o máximo de poder no sistema óptico do olho mais amétrope. A lógica é que, diminuindo-se a diferença de poder entre os olhos, diminui-se também a aniseiconia associada a ela. A seguir, veremos como se consegue isso.

\section{ASSOCIAÇÃO LENTE-AR-OLHO}

O desenho da figura 4 apresenta um olho afácico de +43 D, 


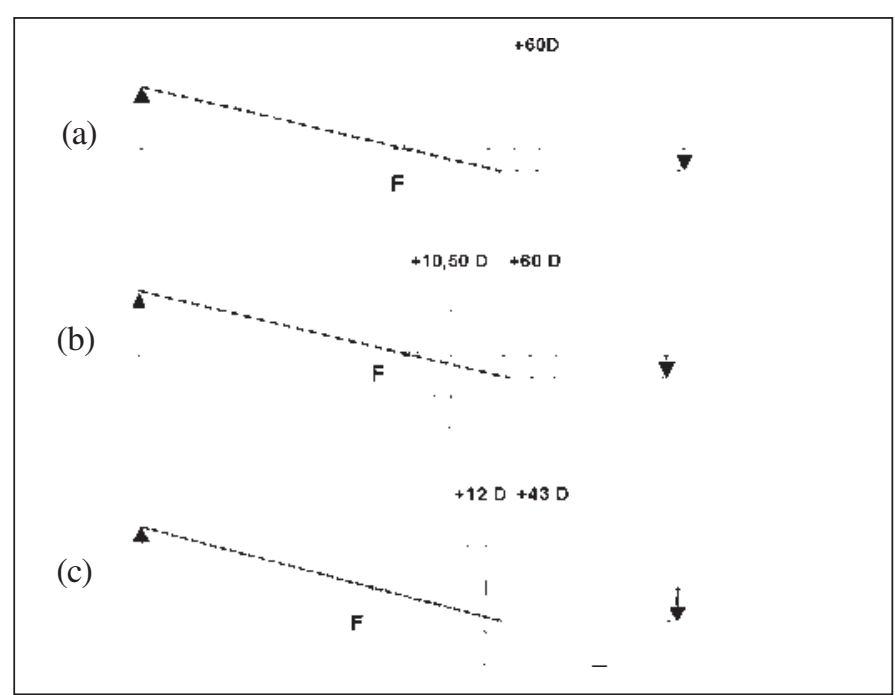

Figura 3 - Efeitos da correção da anisometropia. F: foco anterior do olho

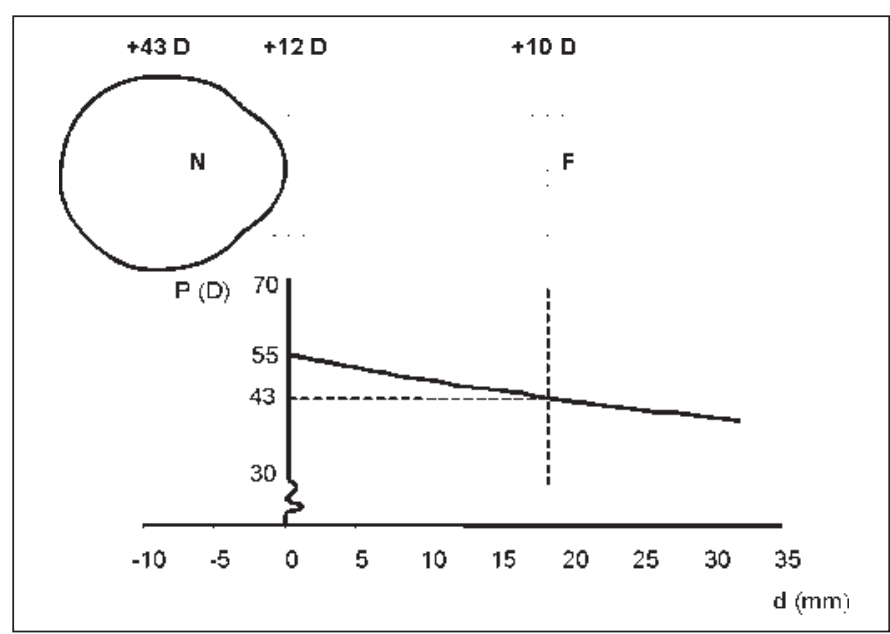

Figura 4 - Efeito da correção óptica sobre o poder da associação lente-olho. F: foco anterior do olho; N: ponto nodal; d: distância da lente ao ponto nodal

corrigido por uma lente de $+12 \mathrm{D}$, no plano da córnea ou, alternativamente, por uma lente de +10 D colocada a 17 milímetros da mesma. Por mais estranho que pareça, o poder da associação lente-ar-olho não pode ser deduzido diretamente, porque varia com a separação dos seus elementos. Isso é mostrado, com detalhes, no gráfico da parte inferior da figura onde se representa, em abscissas, as distâncias "d", que separam a lente do ponto nodal e, em ordenadas, o poder da associação lente-ar-olho.

O primeiro fato de destaque é que o poder máximo da associação, representado pela soma algébrica dos seus elementos ópticos, ou seja, +43 D +12 D = +55 D, só se verifica quando a lente está em contato com a córnea $(\mathrm{d}=0)$. Isto explica por que as lentes de contato são mais eficazes que as de óculos na correção das anisometropias refrativas. Por introduzirem máximo poder no sistema lente-ar-olho, têm maio- res chances de neutralizar as eventuais desigualdades dióptricas com o olho vizinho.

À medida que a lente é afastada do olho, o poder da associação cai. Tudo se passa como se o ar, existente entre os sistemas, funcionasse como uma lente negativa. Quando a lente assume a posição do foco anterior, o poder da associação, passa a ser igual ao do olho isolado, ou seja, $+43 \mathrm{D}+10 \mathrm{D}=+43 \mathrm{D}$. Essa é obviamente a posição onde a lente menos interfere com o poder do sistema ocular.

Como a estratégia de tratamento das anisometropias axiais é a de não perturbar o equilíbrio original de poder entre os olhos, é essa a posição ideal para a colocação das lentes corretoras (regra de Knapp) ${ }^{(2)}$.

Em outras palavras, se os óculos forem colocados exatamente nos planos dos focais anteriores, eles não alterarão a igualdade de poder entre olhos e, consequentemente, não criarão aniseiconia artificial. É por isso que se diz que as anisometropias axiais devem ser corrigidas com óculos. Mesmo que não sejam colocados exatamente nos planos focais, porque é difícil saber as localizações dos mesmos, ainda assim induzem menos aniseiconia do que se fossem usadas lentes de contato.

\section{NEUTRALIZAÇÃO DA ANISEICONIA}

A aniseiconia pode ser minimizada, mas raramente neutralizada com óculos ou lentes de contato. Uma vez que os olhos com anisometropia axial têm o mesmo poder óptico, a introdução da lente corretora, tende a desfazer o equilíbrio original de poder, gerando aniseiconia. Nas anisometropias refrativas, a lente corretora trata simultaneamente a diferença de poder e a de refração. Entretanto, ela não elimina totalmente a aniseiconia, pelo fato de não neutralizar totalmente a disparidade de poder entre os olhos; seria necessária uma lente intra-ocular para isso. No exemplo da figura 3, a aniseiconia gerada pela afacia é da ordem de $25 \%$, quando corrigida com óculos, e de $9 \%$, quando corrigida com lentes de contato.

A aniseiconia é calculada dividindo-se o tamanho da imagem focada na retina, do olho mais amétrope pelo tamanho da imagem focada na retina, do menos amétrope. Para entendermos a lógica desses cálculos é preciso distinguir as imagens ópticas das retinianas ${ }^{(3)}$.

As imagens ópticas são formadas pelo sistema óptico ocular sem considerar a retina. O tamanho da imagem óptica é inversamente proporcional ao poder do sistema ocular. As imagens retinianas são as que caem na retina, independentemente de estarem ou não focadas. O tamanho dessas imagens depende da distância entre o ponto nodal e a retina e nada mais. Ver a figura 2.

Quando as imagens de ambos os olhos estão focadas nas retinas, com óculos ou lentes de contato, as imagens ópticas confundem-se com as retinianas. Com isso, os tamanhos das imagens retinianas, também ganham a propriedade de serem inversamente proporcionais aos poderes dos sistemas ópticos que lhes dão origem. A razão entre os tamanhos das imagens pode então ser substituída por uma razão de poderes, na qual 
o olho menos amétrope vai para o numerador e o olho mais amétrope, para o denominador.

Se o resultado for maior que a unidade teremos uma ampliação; se for menor, teremos uma minimização. Os valores são geralmente apresentados na forma de porcentagens. Na figura 3 , considerando $\mathrm{I}_{\mathrm{a}}$ e $\mathrm{P}_{\mathrm{a}}$ o tamanho da imagem focada e o poder do sistema óptico de "a", respectivamente e $\mathrm{I}_{c}$ e $\mathrm{P}_{c}$, o tamanho da imagem focada e o poder do sistema óptico de "c", respectivamente, a razão entre os tamanhos das imagens de "c" e "a" é $\mathrm{I}_{\mathrm{c}} / \mathrm{I}_{\mathrm{a}}=\mathrm{P}_{\mathrm{a}} / \mathrm{P}_{\mathrm{c}}=60 \mathrm{D} / 55 \mathrm{D}=1,09$. A imagem de "c" é $9 \%$ maior que a de "a".

\section{ANISOFORIA}

Embora, os óculos sejam mais apropriados para as anisometropias axiais e as lentes de contato para as refrativas, a freqüência de queixas de astenopia parece ser sempre maior com os óculos. Quantas pessoas se conhecem, que passam a queixarse de astenopia quando os óculos são substituídos por lentes de contato ou por cirurgia refrativa? A resposta é: muito poucas. Por causa dessa observação, há uma corrente de partidários da opinião que o maior problema da correção das anisometropias é a anisoforia e não a aniseiconia ${ }^{(4)}$. Vejamos por que.

Toda lente tem efeito prismático que é nulo no centro e aumenta em direção à periferia. Quanto maior o poder dióptrico, maior a progressão prismática. Um par de óculos, com lentes de poderes diferentes submeterá os olhos a efeitos prismáticos distintos, sempre que o olhar estiver fora dos centros ópticos. Isso tende a provocar desalinhamentos dos eixos visuais - anisoforias - que terão de ser compensados pela fusão. $\mathrm{O}$ esforço fusional extra gera astenopia, particularmente no olhar vertical, onde a amplitude de fusão é mais limitada. O problema normalmente não ocorre com as lentes de contato, porque o olhar é feito pelo centro das mesmas.

\section{ANISOMETROPIA AXIAL OU REFRATIVA?}

Como saber se uma anisometropia é axial ou refrativa? Com o auxílio do biômetro ultra-sônico e da ceratometria pode-se ter idéia razoável do tipo de anisometropia. Entretanto, é improvável que alguém de bom senso venha utilizá-los clinicamente, com essa finalidade. De modo grosseiro, pode-se admitir que as anisometropias associadas à miopia alta tendem a ser axiais; as associadas às variações de índice de refração do cristalino e à afacia, do tipo refrativo. A maioria dos casos, no entanto, veicula mistura dos dois tipos.

\section{PALAVRAS FINAIS}

Com tantas variáveis, há de se convir que é muito difícil estabelecer uma conduta padronizada para as anisometropias. Somente com tirocínio, sensibilidade e bom senso é que se pode conseguir os melhores resultados. O exemplo a seguir, ilustra essa recomendação.
A Sra. Maria Auxiliadora, de 42 anos, apresentava a seguinte refração, dez anos após ter se submetido à cirurgia de ceratotomia radial para miopia:

$\mathrm{OD}=+6,0$ esf $\mathrm{x}-5$ cil 30

$\mathrm{OE}=+2,0$ esf $\mathrm{x}-9$ cil 165

Vinha trazendo quatro óculos recentes, alegando que nenhum deles havia resolvido seu problema, que era o de melhorar a visão de perto, para continuar exercendo a profissão de escriturária. Observamos que todos eles corrigiam insuficientemente a hipermetropia e o astigmatismo. Já haviam sido tentadas lentes de contato, mas estas não paravam nos olhos, devido ao miserável estado das córneas.

Testando a correção total, observamos que a visão chegava a 0,5 no olho direito e 0,4 no esquerdo. Com isso, ela conseguia enxergar o suficiente para ganhar a vida. Após uma longa preleção, na qual foi-lhe alertado sobre possíveis sintomas de cefaléia, náusea e distorções visuais, prescrevemos o total. O retorno foi agendado para quinze dias. A consulta terminou com a observação: - no início, a senhora vai odiar seus óculos, mas tenho certeza que, com o tempo, conseguirá usá-los! No dia marcado, tomamos o cuidado de deixar o segurança passeando pelo corredor, atento a algum sinal de socorro. Qual não foi a surpresa de ver um rosto sorridente dizendo: - doutor, o senhor merece um beijo! Estou conseguindo trabalhar e não senti um décimo do que me alertou.

Onde foi que acertamos e os outros não? Percebemos que o problema era a falta de visão e transmitimos confiança ao antecipar, com uma pitada de exagero, os possíveis dissabores que a paciente teria de enfrentar para enxergar decentemente. Foi exercitado o bom senso, acima de tudo. Pode-se argumentar, então, que aquele que ignorasse completamente o assunto também teria feito prescrição semelhante. É até possível, mas sem base sólida no assunto, é improvável que tivesse transmitido segurança para que a cliente usasse seus óculos.

\section{ABSTRACT}

The paper presents a revision of the anisometropias. It discusses the definition, classification and probable optical and physiological mechanisms of the symptoms. There are no rigid rules for the condition's treatment; each case has to be managed individually.

Keywords: Anisometropias; Ametropia; Refractive errors

\section{REFERÊNCIAS}

1. Michaels DD. Visual optics and refraction; a clinical approach. Saint Louis: C. V. Mosby; 1975. p.343.

2. Ogle KN. Optics: an introduction to ophthalmologists. $2^{\text {nd }}$ ed. Springfield, Ill: Charles C. Thomas; 1968. p.205.

3. Sampson WG. Optical principles of contact lens fitting. In: Girard JL editor. Corneal contact lenses. $2^{\text {nd }}$ ed. Saint Louis: C.V. Mosby; 1970. p.51-2.

4. Miller D. Aniseiconia. Optics and refraction: a user-friendly guide. In: Poddos SM, Yanoff M editor. Textbook of ophthalmology. New York: Gower Medical; 1991. p.10.14. 